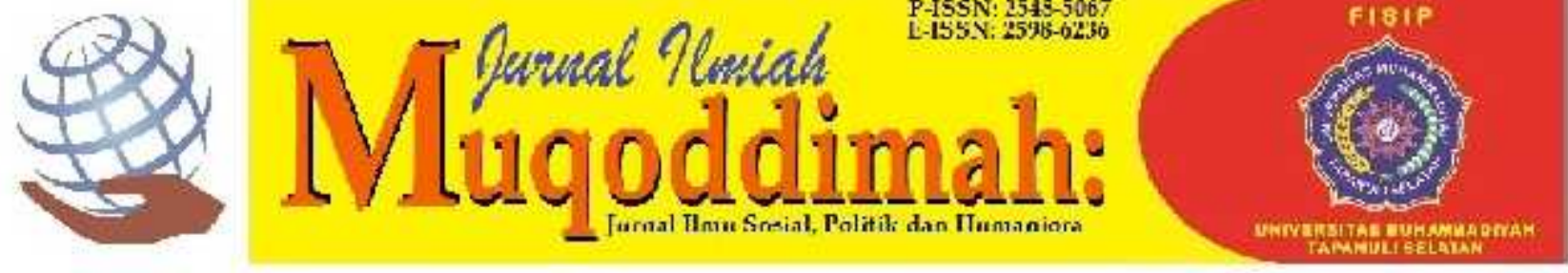

\title{
Analisis Penyebab Peredaran Narkoba di Lembaga Pemasyarakatan Kelas II A Curup Menggunakan Diagram Fishbone
}

\author{
Luthfi Madani $\mathrm{R}^{1 \text { ) }}$ Arisman ${ }^{2)}$ \\ Politeknik IImu Pemasyarakatan, Bengkulu, Curup, Indonesia ${ }^{1)}$ \\ Politeknik IImu Pemasyarakatan, Depok, Cinere, Indonesia Jl. \\ Raya Gandul, No. 4, Rt.05/Rw.06, Kelurahan Gandul, Cinere, \\ Depok, Jawa Barat, $35612^{2)}$ \\ luthfimadaniramansyah99@gmail.com ${ }^{1)}$ \\ arismanbpsdm@gmail.com ${ }^{2}$
}

\begin{abstract}
Abstrak
Dalam melakukan tugas di lembaga pemasyarakatan, diperlukan tingginya tingkat keamanan di Lapas agar berlangsung dengan maksimal. Fokus masalah ini adalah keamanan yang tidak berjalan dengan maksimal mengakibatkan adanya peredaran barang terlarang narkotika yang berlokus di Lapas kelas II A Curup. Tujuan dari pada penelitian ini adalah untuk mengetahui faktor apa saja yang menyebabkan terjadinya peredaran narkoba melalui pendekatan studi kasus dan wawancara, yang data nya kemudian diolah dan disajikan dalam bentuk diagram fishbone. Hasil dari penelitian ini adalah perlu adanya suatu perbaikan dalam sistem keamanan, peningkatan sarana dan prasarana serta pengoptimalan kompetensi petugas dan perbaikan tembok dinding Lapas, pagar kawat dan parit gajah sesuai standar pola bangunan pemasyarakatan.
\end{abstract}

Kata kunci: Narkoba, Narapidana, Fishbone analysis

\begin{abstract}
In carrying out the duties of a correctional institution, it is necessary to have a high level of security in prisons so that it can run optimally. The focus of this issue is security, which does not run optimally, resulting in the circulation of prohibited narcotics items, which are iberlocus in iCurup class II prisons. The purpose of this research is to find out what factors cause drug trafficking to occur through a case study approach and interviews, whose data are then processed and presented in the form of an ifishbone idiagram. $i$ The result of this research is that there is a need for an improvement in the security system, improvement of facilities and infrastructure as well as optimization of the competence of the officers and the repair of the walls of the prison's walls, the iparit iparit fence and the standard iparit ijajah building.
\end{abstract}

Keywords: Drugs, Prisoners, Fishbone analysis

Volume 5, Nomor 2, Agustus 2021 


\section{PENDAHULUAN}

Lembaga Pemasyarakatan sebagai lembaga correction merupakan salah satu komponen penting dalam sistem peradilan pidana yang memiliki fungsi paling strategis serta potensial untuk memperbaiki para narapidana agar dibina sehingga diharapkan mampu menjalani kehidupan kedepan lebih baik lagi. Menurut UU No. 12 Tahun 1995 tentang pemasyarakatan pasal 2, tujuan pemasyarakatan adalah sistem pemasyarakatan diselenggarakan dalam rangka membentuk warga Binaan Pemasyarakatan agar menjadi manusia seutuhnya, menyadari kesalahan, memperbaiki diri dan tidak mengulangi tindakan pidana sehinga dapat kembali diterima di masyarakat, sehingga dapat berperan kembali sebagai anggota masyarakat yang bebas dan bertanggung jawab.

Namun kenyataan walaupun narapidana sudah dimasukkan ke dalam Lembaga pemasyarakatan, bukan berarti menutup kemungkinan bahwa narapidana mencoba untuk memakai dan juga mengulangi apa yang dilakukannya diuar lingkup Lembaga pemasyarakatan. Para pecandu narkoba ini tidak segan-segan untuk dapat berbuat diluar kendali petugas dan diluar dari pemantauan para petugas. Apapun cara dilakukan untuk dapat memenuhi Hasrat untuk memakai barang haram ini.

Di Lembaga Pemasyarakatan kelas II A Curup tahun 2021 data terakhir jumlah narapidana berjumlah 530 orang dan yang menjadi pemakai dan pecandu narkoba sekitar $40 \%$. Hal ini sangat mengkhawatirkan karena sangat membuat kondisi dan situasi yang tidak kondusif di dalam Lembaga pemasyarakatan karena banyaknya pecandu narkoba yang sangat ingin memakai Kembali karena proses rehabilitasi yang tidak benar-benar dilakukan, melainkan hanya memakainya di dalam Lembaga pemasyarakatan saja. Narapidana ini berusaha untuk terus memasukkan benda haram tersebut. Baik melalui makanan yang dibawa oleh keluarga, dilempar dari tembok lapas, maupun dari para petugas Lembaga pemasyarakatan. Hal apa saja dapat kemungkinan terjadi sehingga para pimpinan harus dapat mengatasi dan mencarikan solusi yang tepat.

"Di mana ada tersangka atas inisial KMK, AW, AG, A, MI, dan AL yang merupakan terpidana di lapas dengan hukuman di atas 10 tahun dan hukuman mati," kata Sigit saat jumpa pers di Mabes Polri, Jakarta, Rabu, 28 April 2021.

Polri mengungkap kasus peredaran narkoba jenis sabu seberat 2,5 ton dari jaringan internasional, setelah bekerja sama dengan Ditjen Bea dan cukai Kementerian Keuangan, Drug Enforcement Administration (DEA) dan Dirjen Pemasyarakatan Kemenkumham.

Peredaran narkoba yang dilakukan dapat melalui pegawai, kiriman makanan pengunjung, lemparan barang dari luar Lembaga pemasyarakatan dll. Sebagai Lembaga Pemasyarakatan Kelas II seharusnya sudah cukup mampu mendeteksi gangguan keamanan dan ketertiban lapas, memiliki berbagai teknologi digital yang lebih canggih, namun setiap kecanggihan teknologi pasti memiliki kelemahan. Selain dari teknologi digital, pengamanan melalui konsep manual yang dilakukan oleh manusia (petugas) juga dikaitkan dengan lemahnya pengawasan dan pengontrolan setiap sel, dan jumlah petugas keamanan yang lebih sedikit dari pada jumlah hunian yang membuat pengawasan dan control pada setiap blok berjalan tidak maksimal. Oleh sebab itu, penulis bertujuan untuk menganalisis sebab-sebab peredaran narkoba di Lembaga Pemasyarakatan Kelas II A Curup melalui Fishbone Analysis.

\section{METODE}

Penelitian yang digunakan merupakan jenis penelitian kualitatif melalui pendekatan studi kasus. Dengan maksud untuk mengetahui faktor apa saja yang menyebabkan peredaran narkoba bagaimana upaya pencegahan peredaran yang merupakan masalah utama di Lembaga Pemasyarakatan di Indonesia dengan menggunakan analysis fishbone. Penelitian ini dilakukan di Lembaga Pemasyarakatan Kelas II A Curup. Subjek penelitian terdiri atas informan kunci dan informan utama. Informan kunci oleh KPLP dan informan utama dipilih dari subseksi Kamtib sebagai data primer. Teknik pengumpulan Data yang digunakan dalam penelitian ini adalah data primer dan data sekunder. Data primer merupakan data utama yang di peroleh melalui wawancara yang di dapat dari 
individu atau perseorangan dan kemudian melakukan observasi langsung ke lokasi penelitian dan pendokumentasian. Sedangkan data yang diperoleh melalui studi kepustakaan, jurnal, internet maupun buku-buku yang mendukung penelitian ini.

Dalam mengidentifikasi faktor penyebab dan membantu dalam proses pengolahan data agar lebih terstruktur dan mudah untuk di pahami maka menggunakan alat dalam konteks manajemen kualitas yaitu diagram tulang ikan (Fishbone) untuk mengetahui sebab akibat dari permasalahan tersebut. Untuk mencari faktor-faktor penyebab dari permasalahan di atas maka akan di susun berdasarkan teori 5M yang dikemukakan oleh Harrington Emerson, yaitu Man (manusia), Money (anggaran), Method (cara), Materials (prasarana), dan Machines (sarana). Dibuat juga suatu teknik kreativitas dengan mengupayakan pencarian penyelesaian dari suatu masalah tersebut . Istilah brainstorming dipopulerkan ioleh Alex F. Osborn (1940an).

Selain itu penulis juga menggunakan 5W1H untuk melakukan investigasi mendalam dan penelitian terhadap permasalahan di atas. Analisis ini digunakan untuk menemukan sumber-sumber penyebab dari masalah yang ada dalam penelitian ini. 5W1H merupakan singkatan dari 5W (What, Where, Who, When, Why) dan $\mathrm{H}$ (How) oleh (Jens J.Dahlgaard, et all, 2007). 5W1H digunakan juga dalam penelitian ini karena untuk mengetahui penyebab dominan masalah di atas sehingga dapat dilakukan prioritas perbaikan.

HASIL DAN PEMBAHASAN

Tabel 1.1 Data Warga Binaan yang melakukan peredaran narkoba dari Tahun 2016-2020

\begin{tabular}{llllll}
\hline Tahun & No & Nama WBP & Umur & Kasus & $\begin{array}{l}\text { Pidana } \\
\text { Penjara }\end{array}$ \\
\hline 2019 & 1. & Jul & 23 & Narkoba & 9 Tahun \\
& 2. & Aziz & 30 & Pencurian & 10 Tahun \\
2020 & 3 & Gunawan & 21 & PPA & 8 Tahun \\
\hline
\end{tabular}

\section{Sumber : Laporan Narapidana Lapas Kelas II A Curup (2019-2020)}

Melihat cukup banyak nya pelarian yang terjadi di Lapas kelas II A Curup maka dibuatlah suatu analisis dengan menggunakan diagram Fishbone (Tulang Ikan) oleh peneliti untuk dapat menemukan akar "penyebab" terjadinya masalah khususnya pelarian narapidana dimana prosesnya terkenal dengan banyaknya faktor yang berpotensi menyebabkan munculnya peredaran narkoba. Adapun hasil yang menjadi penyebab pelarian narapidana diuraikan dalam fishbone diagram di bawah dengan menggunakan teori $5 \mathrm{M}$ oleh Harrington Emerson.

Gambar 1.1 Fishbone Diagram Faktor Utama Peredaran Narkoba

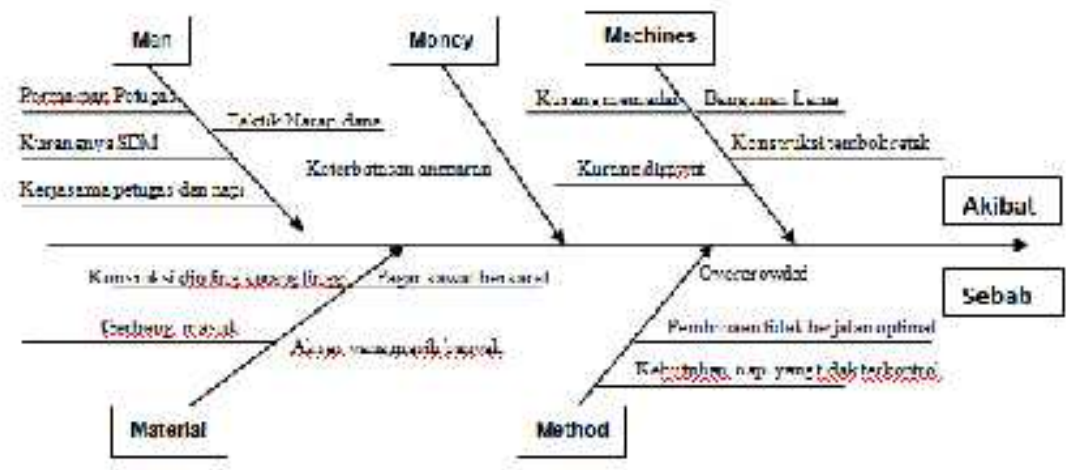


Kemudian setelah dilakukan analisis dengan menggunakan diagram Fishbone, maka didapatlah hasil dengan menggunakan Brainstorming yang bertujuan untuk menjelaskan sebuah analisa atas permasalahan yang dibahas sebagai berikut :

Tabel 1.2 Hasil Brainstorming

\begin{tabular}{|c|c|c|}
\hline Possible iRoot & Discussion & Root \\
\hline Cause & & Cause? \\
\hline \multicolumn{3}{|c|}{ MAN } \\
\hline Kelalaian kerja & Peningkatan SOP terhadap petugas & $\mathbf{Y}$ \\
\hline Kekurangan SDM & $\begin{array}{l}\text { Penambahan petugas pemasyarakatan di } \\
\text { Lapas tersebut }\end{array}$ & $\mathbf{Y}$ \\
\hline $\begin{array}{l}\text { Kerja sama Petugas } \\
\text { dan Napi }\end{array}$ & $\begin{array}{l}\text { Pemberian sanksi tegas terhadap } \\
\text { etikapetugas pemasyarakatan }\end{array}$ & $\mathbf{N}$ \\
\hline Pemeriksaan Petugas & $\begin{array}{l}\text { Memperketat pemmeriksaan kepada petugas Ketika } \\
\text { masuk dan keluar Lapas }\end{array}$ & $\mathbf{N}$ \\
\hline \multicolumn{3}{|c|}{ MACHINES } \\
\hline Bangunan Lama & $\begin{array}{l}\text { Melakukan renovasi untuk bangunan yang } \\
\text { tidak layak dan adanya perawatan }\end{array}$ & $\mathbf{Y}$ \\
\hline $\begin{array}{l}\text { Konstruksi } \\
\text { bangunan lapuk }\end{array}$ & $\begin{array}{l}\text { Memberi tanda/simbol bagi bangunan yangsudah } \\
\text { tidak layak }\end{array}$ & $\mathbf{N}$ \\
\hline Kurang memadai & $\begin{array}{l}\text { Melakukan pembaharuan fasilitas yangurgent } \\
\text { untuk keamanan petugas dan } \\
\text { Narapidana }\end{array}$ & $\mathbf{Y}$ \\
\hline Kurang terawat & $\begin{array}{l}\text { Peningkatan pemeliharaan sarana } \\
\text { yangtersedia }\end{array}$ & $\mathbf{N}$ \\
\hline \multicolumn{3}{|c|}{ MATERIALS } \\
\hline $\begin{array}{l}\text { Pagar } \\
\text { kawatberkarat }\end{array}$ & Mengganti dengan yang baru & $\mathbf{Y}$ \\
\hline $\begin{array}{l}\text { Konstruksi lahan } \\
\text { berada di bawah }\end{array}$ & $\begin{array}{l}\text { Memperkuat keamanan baik dari luar } \\
\text { maupun dari dalam }\end{array}$ & $\mathbf{N}$ \\
\hline $\begin{array}{l}\text { Akses yang } \\
\text { lumayan banyak }\end{array}$ & Mempersempit celah masuknya narkoba & $\mathbf{N}$ \\
\hline Gerbang masuk & Efektivitas penggunaan X-Ray & $\mathbf{Y}$ \\
\hline \multicolumn{3}{|c|}{ METHOD } \\
\hline Over crowded & Pemindahan narapidana & $\mathbf{Y}$ \\
\hline $\begin{array}{l}\text { Pembinaan } \\
\text { tidakberjalan }\end{array}$ & Pengoptimalan pembinaan di perketat & $\mathbf{Y}$ \\
\hline $\begin{array}{l}\text { Kebutuhan napi yang } \\
\text { tidak terkontrol }\end{array}$ & Penguatan kepada napi & $\mathbf{N}$ \\
\hline \multicolumn{3}{|c|}{ MONEY } \\
\hline Tidak adanya & Pengajuan anggaran ke Pusat & $\mathbf{Y}$ \\
\hline
\end{tabular}

Narkotika adalah zat atau obat baik yang bersifat alamiah, sintetis, maupun semi sintetis yang menimbulkan efek penurunan kesadaran, halusinasi, serta daya rangsang. Sementara menurut UU Narkotika pasal 1 ayat 1 menyatakan bahwa narkotika merupakan zat buatan atau pun yang berasal dari tanaman yang memberikan efek halusinasi, menurunnya kesadaran, serta menyebabkan kecanduan.

Obat-obatan tersebut dapat menimbulkan kecanduan jika pemakaiannya berlebihan. Pemanfaatan dari zat-zat itu adalah sebagai obat penghilang nyeri serta 
memberikan ketenangan. Penyalahgunaannya bisa terkena sanksi hukum. Untuk mengetahui apa saja jenis dan bahaya narkoba bagi Kesehatan. Hal ini juga terjadi pada Lembaga Pemasyarakatan Kelas II A Curup, adanya peredaran narkoba diakibatkan oleh sarana yang memang kurang terawat dan kurang memadai, terkhusus dalam hal tembok dinding lapas yang masih pendek dan pagar kawat yang berkarat menyebabkan mudahnya narapidana untuk mendapatkan narkoba dari luar. Ditambah juga melalui wawancara oleh Informan Kunci selaku KPLP Lapas kelas II A Curup mengatakan :

"yang mengakibatkan adanya peredaran narkoba itu ketika adanya Kerjasama petugas dan narapidana untuk memasukkan narkoba kedalam Lembaga pemasyarakatan"

Hal itu tentu sejalan dengan kekurangan petugas atau sumber daya manusia nya dalam menjalankan tugas, dengan kondisi over crowded hampir mencapai $500 \%$ mengakibatkan petugas tidak mampu menjalankan tugasnya dengan optimal. Hendaknya petugas pemasyarakatan dibekali suatu suatu Skill atau keahlian khusus dalam melakukan tugas pengamanan, selain dapat melindungi diri sendiri putugas juga mampu bertahan dalam situasi yang mencekam. Namun, peredaran narkoba juga tidak akan terjadi apabila adanya pengamanan yang sangat ketat. Lapas merupakan tempat untuk membina narapidana menjadi manusia yang lebih baik lagi dengan segala program pembinaan yang dibuat diharapkan mampu membangkitkan semangat narapidana untuk memperbaiki diri. Pembinaan yang berjalan dengan optimal tentu berpengaruh besar terhadap perubahan hidup narapidana.

Setelah dilakukan analisa menggunakan diagram Fishbone dan dilanjutkan dengan Brainstorming, maka langkah terakhir adalah menggunakan metode $5 \mathrm{~W} 1 \mathrm{H}$ untuk mengetahui penyebab dominan masalah di atas sehingga dapat dilakukan prioritas perbaikan sebagai berikut :

Tabel 1.3 Analisis $5 \mathrm{~W}+1 \mathrm{H}$

\begin{tabular}{|c|c|c|c|c|c|c|}
\hline $\begin{array}{l}\text { Faktor } \\
\text { Masalah }\end{array}$ & What & Who & Where & When & Why & How \\
\hline \multirow[t]{2}{*}{ Man } & $\begin{array}{l}\text { Kelalaian } \\
\text { kerja }\end{array}$ & $\begin{array}{l}\text { Pegawa } \\
\text { i }\end{array}$ & $\begin{array}{l}\text { Penjagaa } \\
n\end{array}$ & $\begin{array}{l}2019- \\
2020\end{array}$ & $\begin{array}{l}\text { Belum ada } \\
\text { sanksi dan } \\
\text { pengawasany } \\
\text { ang tegas }\end{array}$ & $\begin{array}{l}\text { Membuat } \\
\text { sanksi } \\
\text { tegasdan } \\
\text { melakukan } \\
\text { pengawas } \\
\text { an }\end{array}$ \\
\hline & $\begin{array}{l}\text { Kekurang } \\
\text { an SDM }\end{array}$ & $\begin{array}{l}\text { Pegawa } \\
\text { i }\end{array}$ & $\begin{array}{l}\text { Penjagaa } \\
\mathrm{n}\end{array}$ & $\begin{array}{l}2019- \\
2020\end{array}$ & $\begin{array}{l}\text { Petugas } \\
\text { pemasyarakata } \\
\mathrm{n} \text { yang } \\
\text { masih } \\
\text { terbatas }\end{array}$ & $\begin{array}{l}\text { Rekruitmen } \\
\text { pegawai } \\
\text { dariCPNS } \\
\text { kemenkumh } \\
\text { am }\end{array}$ \\
\hline $\begin{array}{l}\text { Mac } \\
\text { hines }\end{array}$ & $\begin{array}{l}\text { Banguna } \\
\text { n Lama }\end{array}$ & Lapas & $\begin{array}{l}\text { Tembok } \\
\text { /dindingL } \\
\text { apas }\end{array}$ & $\begin{array}{l}2019- \\
2020\end{array}$ & $\begin{array}{l}\text { Belum adanya } \\
\text { anggaran yang } \\
\text { memadai untuk } \\
\text { melakukanperba } \\
\text { ikan } \\
\text { peninggiantemb } \\
\text { ok } \\
\text { Lapas }\end{array}$ & $\begin{array}{l}\text { Pengajuan } \\
\text { dana } \\
\text { kepadaKe } \\
\text { menterianH } \\
\text { ukum dan } \\
\text { Ham }\end{array}$ \\
\hline $\begin{array}{l}\text { Mat } \\
\text { erials }\end{array}$ & $\begin{array}{l}\text { Pagar } \\
\text { kawat } \\
\text { berkarat }\end{array}$ & Lapas & $\begin{array}{l}\text { Pagar } \\
\text { kawat }\end{array}$ & $\begin{array}{l}2019- \\
2020\end{array}$ & $\begin{array}{l}\text { Dalam } \\
\text { perbaikan } \\
\text { pergantian }\end{array}$ & $\begin{array}{l}\text { Permint } \\
\text { aan } \\
\text { kepada }\end{array}$ \\
\hline
\end{tabular}




\begin{tabular}{|c|c|c|c|c|c|c|}
\hline & & & & & $\begin{array}{l}\text { kawat } \\
\text { yangsudah } \\
\text { Berkarat }\end{array}$ & $\begin{array}{l}\text { DitjenP } \\
\text { as }\end{array}$ \\
\hline & $\begin{array}{l}\text { Gerban } \\
\text { g } \\
\text { masuk }\end{array}$ & Lapas & Lapas & $\begin{array}{l}2019- \\
2020\end{array}$ & $\begin{array}{l}\text { Kekurangan X- } \\
\text { Ray }\end{array}$ & $\begin{array}{l}\text { Permintaan } \\
\text { X-Ray yang } \\
\text { memadai }\end{array}$ \\
\hline Method & $\begin{array}{l}\text { Overcro } \\
\text { wded }\end{array}$ & $\begin{array}{l}\text { Narapi } \\
\text { dana }\end{array}$ & Lapas & $\begin{array}{l}2019- \\
2020\end{array}$ & $\begin{array}{l}\text { Jumlah } \\
\text { narapidana } \\
\text { yang } \\
\text { masuktidak } \\
\text { sebanding } \\
\text { dengan } \\
\text { kapasitas } \\
\text { hunian Lapas }\end{array}$ & $\begin{array}{l}\text { Melakuka } \\
\mathrm{n} \\
\text { pemindah } \\
\text { anbeberap } \\
\text { a } \\
\text { narapidan } \\
\text { a untuk } \\
\text { menguran } \\
\text { gi } \\
\text { overcrowd } \\
\text { ed }\end{array}$ \\
\hline Money & $\begin{array}{l}\text { Anggara } \\
\mathrm{n}\end{array}$ & $\begin{array}{l}\text { Lapas } \\
\text { Curup }\end{array}$ & $\begin{array}{l}\text { Lapas } \\
\text { Curup }\end{array}$ & $\begin{array}{l}\text { 2019- } \\
\text { samp } \\
\text { ai saat } \\
\text { ini }\end{array}$ & $\begin{array}{l}\text { Belum } \\
\text { teralokasinya } \\
\text { dana untuk } \\
\text { renovasi } \\
\text { keamanan } \\
\text { Lapas }\end{array}$ & $\begin{array}{l}\text { Pengajuan } \\
\text { anggaran } \\
\text { kepada } \\
\text { Pusat }\end{array}$ \\
\hline
\end{tabular}

\section{SIMPULAN DAN SARAN}

Dari pembahasan diatas maka dapat di ambil kesimpulan bahwa peredaran narkoba disebabkan oleh sarana seperti tembok dinding Lapas dan pagar kawat yang kurang memadai, prasarana dengan teknologi dan juga alat sarana yang bagus, serta keinginan dari pada narapidana itu sendiri untuk melakukan pemakaian narkoba kembali, ditambah dengan kurang nya SDM untuk pengoptimalan sistem keamanan. Maka dari itu perlu adanya suatu upaya-upaya untuk meminimalisir terjadinya pelarian narapidana kembali d Lapas kelas II A Jambi sebagai berikut :

1. Upaya Pre-emtif

Upaya ini dapat dilakukan dengan cara penguatan yang mana sekarang ini bukan lagi melakukan sistem pemenjaraan melainkan kini beranjak menjadi pemasyarakatan, memulihkan kembali hidup kehidupan dan penghidupan. Apabila nilai-nilai ini dapat diterapkan dan di pahami oleh WBP, niscaya segala niat dan dorongan untuk menggunakan kembali narkoba tidak akan terjadi.

2. Upaya Preventif

Upaya ini masih dalam tahap pencegahan yang merupakan suatu tindak lanjut dari upaya Pre-emtif di atas. Di dukung oleh SDA dan SDM dalam membatasi niat pelarian narapidana seperti :

a. Penambahan Petugas Lapas

b. Memperbaiki bangunan dan fasilitas keamanan Lapas

3. Upaya Represif

Upaya ini dilakukan ketika terdapat peredaran narkoba telah terjadi dengan cara menindak pelakukejahatan sesuai dengan perbuatan nya serta memberi nya sebuah pelajaran untuk memperbaiki diri agar WBP sadar akan perbuatan yang di lakukannya telah melanggar hukum dan merugikan masyarakat terkhusus membuat masyarakat panik dan timbul rasa ketidakpercayaan masyarakat kepada Aparat Penegak Hukum (SPH). Untuk itu upaya represif dapat dilakukan dengan :

a. Hukuman Disiplin

b. Pemindahan narapidana ke lapas lain 


\section{UCAPAN TERIMAKASIH}

Peneliti mengucapkan terima kasih kepada Lapas Kelas II A Curup sebagai lokus penelitian dan segenap informan yang bersedia untuk di wawancarai serta seluruh partisipasi dari pegawai Lapas Kelas II A Curup yang mendukung penelitian ini, semoga hasil dari penelitian ini dapat dijadikan bahan perbaikan dan pedoman bagi Lapas-lapas di seluruh Indonesia untuk lebih memajukan system keamanan dan pembinaan agar berjalan dengan optimal sesuai Undang-Undang Nomor 12 Tahun 1995.

\section{DAFTAR PUSTAKA}

Casban. (2018). Analisis Penyebab Kecelakaan Kerja Pada Proses Washing Container di Divisi Cleaning Dengan Metode Fishbone Diagram Dan SCAT.JISI: Jurnal Integrasi Sistem Industri, 5(2), 111-121.

Dahlan, M., Irdan, M., Studi, P., Masyarakat, K., Al, U., \& Mandar, A. (2021). FISHBONE ANALYSIS SEBAGAI METODE DALAM PENCEGAHAN. 2, 59-62.

Hamja, H. (2016). Model Pembinaan Narapidana Berbasis Masyarakat

(CommunityBased Corrections) Dalam Sistem Peradilan Pidana. Mimbar Hukum - FakultasHukum Universitas Gadjah Mada, 27(3), 445. https://doi.org/10.22146/jmh.15882

Nur, M. I., Wibowo, P., \& Pemasyarakatan, P. I. (2021). INDONESIA. 8(1), 194-203.

Yusdinata, Z., Bora, M. A., Arofah, N., Baja, L., Riau, K., Studi, P., Industri, T., Tinggi, S., Ibnu, T., \& Pte, O. (2018). ANALISIS PENERAPAN KESELAMATANDAN KESEHATAN KERJA (K3 ) DENGAN MENGGUNAKAN METODE FISHBONE. 3(2), 127-133.

Suharyanti Ni Putu Noni, "Modus Penyelundupan Narkotika dan Upaya Penanggulangannya di Lembaga Pemasyarakatan Kelas II A Denpasar" Jurnal Hukum, Vol. 4, No. 1, Mei 2015, hlm. 112-125

Wirmyanti Ni Luh Novi dan Remaja I Nyoman Gede, "Penanggulangan Peredaran Narkotika di Lembaga Pemasyarakatan Kelas II B Singaraja", Jurnal Hukum, Vol. 6 No. 2, Desember 2018, hlm. 17-23

Sari Risa Andika, Suhaimi, Muazzin, 'Upaya Terpadu Pencegahan dan Pemberantasan Penyalahgunaan Peredaran Gelap Narkotika di Lapas Kelas II A Banda Aceh dan Rutan Kelas II B Sigli", Jurnal Hukum, Vol. 2, April 2018, hlm. 152-169

Pamungkas, Apriliantin Putri, 2017, "Peran ASEANAPOL dalam Pemberantasan Peredaran Narkoba di Indonesia", Journal of International Relations, Volume 3, Nomor 2,

Julianan Lisa FR, Nengah Sutrisna W, 2013, Narkotika,Psikotropika dan gangguan jiwa, Yogyakarta: Nuha Medika.

Helviza, Ira, Zulihar Mukmin dan Amirullah, 2016, "Kendala-Kendala Badan Narkotika Nasional (bnn) Dalam Penanggulangan Penyalahgunaan Narkotika di Kota Banda Aceh, Jurnal IImiah Mahasiswa Pendidikan Kewarganegaraan Unsyiah Volume1, Nomor 1, url: https://media.neliti.com/media/publications/187604. 